\title{
Cardiovascular Autonomic Neuropathy in Patients with Diabetes in Cotonou, Benin: A Cross-Sectional Study
}

Gninkoun Comlan Jules ${ }^{1 *}$, Fanou Joseph Soglo ${ }^{1}$, Alassani Adebayo Sabi Cossi ${ }^{1}$, Djrolo François ${ }^{1}$

Faculty of Health Sciences - Department of Internal Medecine, Service d'Endocrinologie \& Diabétologie du CNHU-HKM, COTONOU - BENIN.

*Corresponding Author: Gninkoun Comlan Jules, Faculty of Health Sciences - Department of Internal Medecine, Service d'Endocrinologie \& Diabétologie du CNHU-HKM, COTONOU - BENIN.

\section{Received Date: 24 July 2021 | Accepted Date: 20 August 2021 | Published Date: 31 Augusł 2021}

Citation: G C Jules, F J Soglo, A A S Cossi, D François. (2021) Cardiovascular Autonomic Neuropathy in Patients with Diabetes in Cotonou, Benin: A Cross-Sectional Study. J. Endocrinology and Disorders. 5(5): DOI:10.31579/2640-1045/083

Copyright: ( 2021 Gninkoun Comlan Jules. This is an open-access article distributed under the terms of the Creative Commons Attribution License, which permits unrestricted use, distribution, and reproduction in any medium, provided the original author and source are credited.

\begin{abstract}
Background: Diabetes mellitus is well known as a major risk factor for cardiovascular diseases. Cardiovascular autonomic neuropathy is one of the diabetes complications that has a major impact on cardiovascular morbidity and mortality in patients with diabetes.
\end{abstract}

Aim: To determine the prevalence of cardiovascular autonomic neuropathy in patients with diabetes attending the diabetic center in Cotonou and to identify its risk factors.

Materials and Methods: It was a cross-sectional study. Cardiovascular autonomic neuropathy was identified using deep breathing test, standind test and the blood pressure response to standing test (orthostatic hypotension). Chi square test was used for statistical analysis and différence was considered significant when $\mathrm{p}<0.05$.

Results : A total of 405 subjects were included in the study. Their mean age was $53.67 \pm 11,68$ years and the mean diabetes duration was 6.66 years. The prevalence of cardiovascular autonomic neuropathy was $65.9 \%$. Regarding the severity of the complication in neuropathic patients, $51.7 \%$ of them had an early neuropathy, $41.2 \%$ have presented a moderate neuropathy and $7.1 \%$ have presented a severe neuropathy.

Factors associated with cardiovascular autonomic neuropathy were age of patients $(p=0.0002)$, diabetes duration $(\mathrm{p}=0.0012)$, hypertension $(\mathrm{p}=0.0015)$, dyslipidemia $(\mathrm{p}=0.027)$ and high pulsed blood pressure $(\mathrm{p}=0.032)$

Conclusion: Cardiovascular autonomic neuropathy is a very frequent complication of diabetes mellitus. Unfortunately this complication of diabetes is not often explored in the patient's follow-up examination. As this complication is recognised to be associated with high cardiovascular morbidity and mortality, systematic screening can be recommanded in patients with long duration of diabetes or presenting another cardiovascular risk factor.

Key words: diabetes ; cardiovascular autonomic neuropathy ; orthostatic hypotension ; microangiopathy

\section{Introduction}

The epidemic trend of the evolution of diabetes mellitus (DM) worldwide [1] is a worrying situation particularly in regard to its numerous complications [2,3]. Because of these complications diabetes mellitus is considered as a very serious disease with high morbidity and mortality [4]. Through available data cardiovascular complications appear as the main cause of mortality in patients with diabetes, mainly the ischemic heart disease $[5,6]$. Cardiovascular autonomic neuropathy has been recognised to inhence cardiovascular morbidity and mortality in patients with diabetes $[7,8]$.
This complication is not often explored during classic patient's follow-up examination. No epidemiological study had been conducted in our population of patients. The present study aimed to determine the prevalence of cardiovascular autonomic neuropathy in patients with diabetes attending the diabetic center in Cotonou and to identify associated factors.

\section{Materials and methods}

It was a cross-sectional study with prospective data collection. Study population was constitued by patients with diabetes of both genders attending the diabetic center of Cotonou. Patients were included with their 
own consent without distinction of type of diabetes. Sampling technique used was a two steps selection in the patient's medical file attending the center. Data data were collected using a questionnaire established for the needs of the study for individual interview and clinical examination. Cardiovascular autonomic neuropathy was defined according to the Toronto Consensus Panel on Diabetic Neuropathy [9]. To assess cardiac autonomic neuropathy, three tests were used: the two cardio-vagal tests (deep breathing test and standing test) and the blood pressure response to standing (orthostatic hypotension).

\section{Inclusion criteria}

All diabetic patients who attend the outpatient center and who have given their consent have been included.

\section{Exclusion criteria}

Patients with a known history of neuropathy and hereditary heart disease, pregnant women, patients with hyperthermia, and patients with a previously known respiratory pathology have been exluded.

\section{Sample size}

Sample size has been calculted using the Openepi software by considering $\mathrm{p}=60$ (mean frequency of cardiac autonomic neuropathy). Then we obtained 369 subjects which were increased by $10 \%$ being 405 to minimize the possible bias due to possible missing data.

\section{Deep breathing test}

With the patient in suppine position, he adapts to a deep and ample breath at a rate of about six cycles per minute. With the help of a pulse oximeter placed on one of his fingers, the highest heart rate that is reached during deep inspirations (HR max) and the minimum heart rate reached during deep expirations were recorded. The difference between the two heart rates was calculated. A difference more than 15 was considered normal and a difference less than 10 was considered abnormal [10].
The patient initially in suppine position gets up with the pulse oximeter still in one of his fingers. The heart rates at 15 and 30 seconds after orthostatism respectively HR max and HR min were taken and noted; then the difference between the two rates was calculated. A difference more than 15 was considered normal and a difference less than 10 was considered abnormal [10].

\section{Blood pressure response to standing}

Orthostatic hypotension has been defined as an excessive fall in BP level (a drop of $>20 \mathrm{mmHg}$ systolic or/and $>10 \mathrm{mmHg}$ diastolic BP) within 3 min of standing and a fall of $30 \mathrm{mmHg}$ systolic BP when a person assumes a standing position

Patient was considered having cardiovascular autonomic neuropathy when one of the three tests was abnormal. Cardiac autonomic neuropathy was considered early when one cardiovagal test was abnormal, confirmed when the two cardiovagal tests were abnormal and severe when the abnormality of the two tests was associated with orthostatic hypotension. [9]. Factors investigated in this study of cardiovascular autonomic neuropathy were age and sexe of patients, diabetes duration, type of treatment, control of the diabetes and the presence of cardiovascular risk factors. Pulsed pressure was difined as the difference between systolic and diastolic pressure.

Statistical analysis were performed using the Chi square test. Difference observed was considered significant when $p \leq 0.05$. Logistic regression test was used for multivariate anlysis for factors assosiated with cardiovascular autonomic neuropathy in univariate analysis.

\section{Results}

A total of 405 patients living with diabetes were included in this study. Women represented $72.8 \%$ of the study population and this population was largely dominated by type 2 diabetes. Characteristics of the population are shown in table 1.

\section{Standing test}

\begin{tabular}{|c|c|}
\hline & $\begin{array}{c}\text { Mean } \pm \text { SD or } \\
\text { N (\%) }\end{array}$ \\
\hline Age (year) & $53.67 \pm 11.68$ \\
\hline Sexe (Female) & $294(72.6)$ \\
\hline Diabetes duration (year) & $6.66 \pm 6.47$ \\
\hline Abdomonal obesity (\%) & $304(75.1)$ \\
\hline High blood pressure (\%) & $188(46.4)$ \\
\hline Type 2 diabetes (\%) & $398(98.27)$ \\
\hline
\end{tabular}




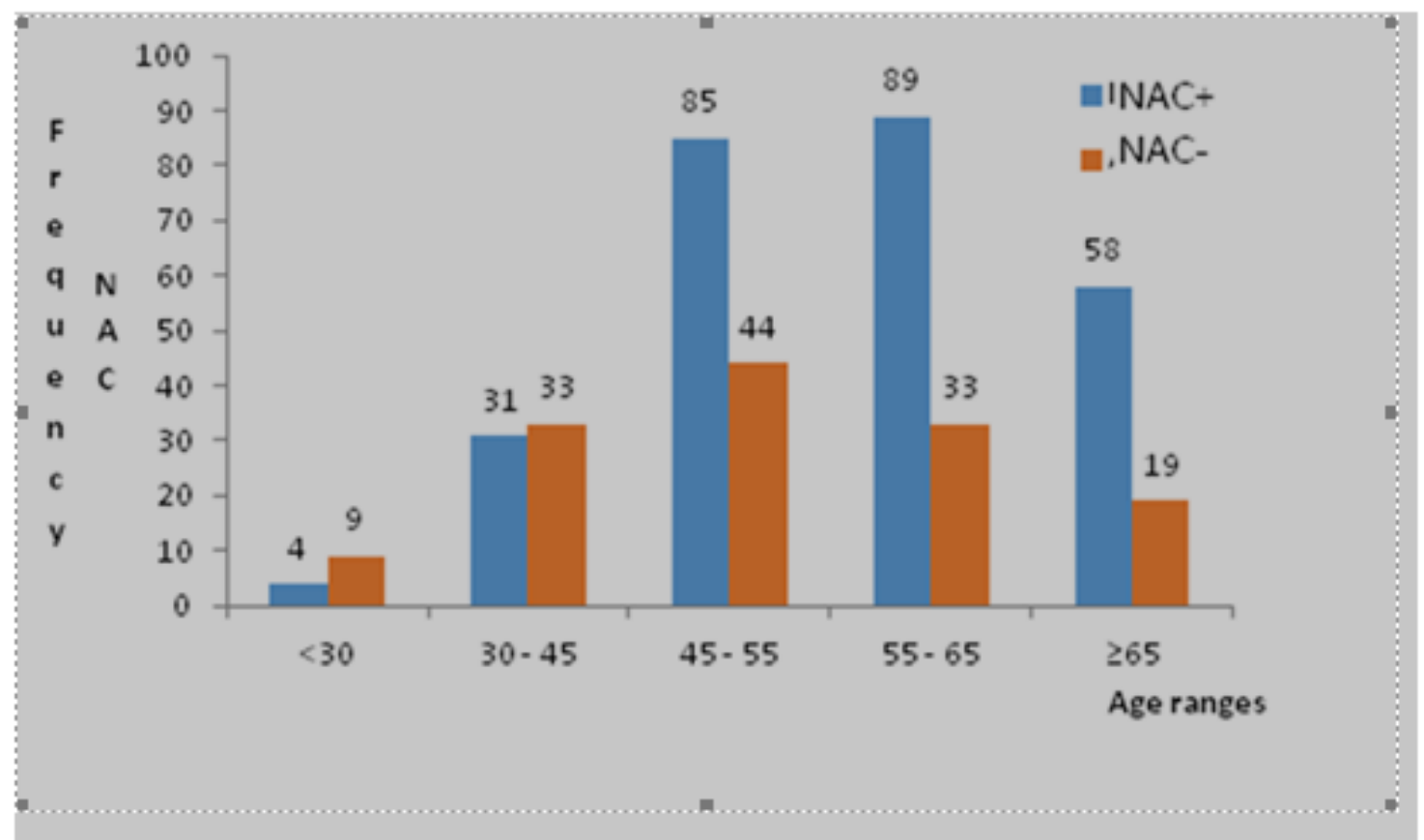

Figure 1: Age and cardiac autonomic neuropathy (CAN).

As shown in this figure, the prevalence of cardiac autonomic neuropathy significant association between age and cardiac autonomic neuropathy increaed with the age of patients and the statistical analysis has shown a with $\mathrm{p}=0.002$.

\begin{tabular}{|c|c|c|c|c|}
\hline \multicolumn{2}{|c|}{ Factors } & \multirow{2}{*}{$\begin{array}{c}\text { Number } \\
\text { investgated }\end{array}$} & \multirow{2}{*}{$\begin{array}{c}\begin{array}{c}\text { Prevalence of cardiac } \\
\text { autonomic neuropathy }(\%)\end{array} \\
67.6 \\
\end{array}$} & $\mathbf{p}$ \\
\hline \multirow[t]{2}{*}{ Sexe } & $\mathrm{M}$ & & & \multirow{2}{*}{$\begin{array}{c}\mathbf{p} \\
0.668\end{array}$} \\
\hline & $\mathrm{F}$ & 294 & 65.3 & \\
\hline \multirow[t]{4}{*}{ Level of eduction } & Non scolarised & 156 & 66.7 & \multirow{4}{*}{0.374} \\
\hline & Primary level & 107 & 71 & \\
\hline & Secondary level & 110 & 62. & \\
\hline & University level & 32 & 56.3 & \\
\hline \multirow[t]{2}{*}{ Diabetes duration (years) } & $<5$ & 216 & 58.8 & \multirow[t]{2}{*}{0.0012} \\
\hline & $\geq 5$ & 189 & 74.1 & \\
\hline \multirow[t]{3}{*}{ Diabetes treatment } & $\begin{array}{c}\text { Diete only } \\
\text { Oral medication }\end{array}$ & $\begin{array}{c}28 \\
300\end{array}$ & $\begin{array}{c}60.7 \\
66\end{array}$ & \multirow{3}{*}{0.128} \\
\hline & Insuline & 44 & 56.8 & \\
\hline & Oral medication + Insuline & 33 & 81.8 & \\
\hline \multirow{2}{*}{$\begin{array}{c}\text { Diabetes control } \\
(\text { HbA1c) }\end{array}$} & $\leq 7 \%$ & 33 & 65.6 & \multirow[b]{2}{*}{0.594} \\
\hline & $>7 \%$ & 142 & 70.4 & \\
\hline
\end{tabular}

Table 2: Associated factors with CAN

There was no association of sexe with cardiac autonomic neuropathy and wether the diabetes was treated with insulin or oral medication had no influence on the prevalence of cardiovascular autonomic neuropathy.

\begin{tabular}{|c|c|c|c|c|}
\hline \multicolumn{2}{|c}{ Factors } & $\begin{array}{c}\text { Population } \\
\text { investigated }\end{array}$ & $\begin{array}{c}\text { Prevalence of } \\
\text { autonomic } \\
\text { neuropathy (\%) }\end{array}$ & \multirow{2}{*}{ p } \\
\hline \multirow{2}{*}{ Abdominal obesity } & Yes & 304 & 66.1 & \multirow{2}{*}{0.887} \\
\cline { 2 - 4 } & No & 132 & 63.6 & \\
\hline Alcohol consumption & Yes & 19 & 63.2 & \multirow{2}{*}{0.794} \\
\cline { 2 - 4 } $\begin{array}{c}\text { Tobacco } \\
\text { consumption }\end{array}$ & No & 386 & 66.1 & \multirow{2}{*}{0.400} \\
\cline { 2 - 5 } & Yes & 7 & 71.4 & \\
\hline \multirow{2}{*}{ High blood pressure } & Yes & 188 & 65.8 & \\
\cline { 2 - 5 } & No & 217 & 73.9 & \\
\hline
\end{tabular}




\begin{tabular}{|c|c|c|c|c|}
\hline \multirow{2}{*}{$\begin{array}{c}\text { Pulsed blood } \\
\text { pressure (mmHg) }\end{array}$} & $<70$ & 367 & 64.3 & \multirow{2}{*}{0.032} \\
\cline { 2 - 4 } Dyslipidemia & $\geq 70$ & 31 & 81.6 & \\
\cline { 2 - 4 } & Yes & 81 & 80.2 & 0.027 \\
\cline { 2 - 4 } & No & 10 & 50.0 & \\
\hline
\end{tabular}

Table 3: Cardiovascular risk factors and autonomic neuropathy

In cardiovascular risk factors investigated, only high blood pressure, pulsed blood pressure and dyslipidemia have shown significant association with cardiac autonomic neuropathy.

\section{Discussion}

Cardiovascular autonomic neuropathy is not investgated in routine follow-up of patients with diabetes. The current study found that the prévalence of cardiac autonomic neuropathy was $65.9 \%$. High prevalences of $73 \%, 88 \%$ and $70 \%$ were also reported respectively by Low et al [11], Kenedy et al [12] and Wael et al [13]. However, low prevalences of $36 \%$ and $35 \%$ were reported respectively by Kempler et al [5] and Pop-Busui et al [14]. The difference observed in these studies can be related to the diagnostic criteria used by the different authors for the selection of patients with cardiovascular autonomic neuropathy. This disparity is thought to be due to the differences in the screening criteria used. Indeed, KEMPLER et al have used the active orthostatic test and blood pressure response to standing and POP-BUSUI et al used deep breathing test, Vasalva maneuver, blood pressure response to standing. In the current study, the criteria used were: the deep breathing test, the standing test and the blood pressure response to standing. Regarding the severity of the complication, a frequency of severe cardiovascular neuropathy was the lower $(9.6 \%)$. The results of this study are in keeping with previous observational studies. Indeed, Ko et al [15] have found frequencies of $51.1 \%, 39.3 \%$ and $9.6 \%$ of respectively early, confirmed and severe cardiovascular autonomic neuropathy.

In our study, mean age of patients was $53.67 \pm 11.68$ years, very closed to 53.03 years reported by Traoré et al [16] and closed to 55.2 years reported by Shera et al [3].As reported by several authors [3, 17-19] prevalence of cardiovascular autonomic neuropathy increased significantly with age of patients. There was no association with the sexe of patients in the present study and these findings are in keeping with those reported by Kempler et al [5].

Prevalence of cardiovascular autonomic neuropathy was significantly associated with diabetes duration. Spallone et al [9], Vinik et al [19] and Valensi et al [20] have reported similar results. This is not surprising since diabetes duration has been reported as independent risk factor for cardiovascular autonomic neuropathy whatever the type of diabetes [21].

In the present study, prevalence of cardiovascular autonomic neuropathy was significantly higher in patients with high blood pressure. This result was conform to what has been reported by Boulton et al [22], Ko et al [15] and Ayad et al [23].

An other cardiovascular risk factor significantly associated with cardiovascular autonomic neuropathy was dyslipidemia. Same observation had been made by several other authors [12, 24, 25]. Dyslipidemia had also been reported as progressing factor of cardiovascular autonomic neuropathy [26].

Obesity is a factor currently described to be associated with cardiovascular autonomic neuropathy [20, 27, 28]. This association did not appear in our study certainly because in our analysis obesity was not isolated but pooled with overweight.

\section{Conclusion}

Cardiovascular autonomic neuropathy is a very frequent complication of diabetes mellitus but not often investiagated in patients follow up. Our study revealed a high prevalence of cardiovascular autonomic neuropathy in patients with diabetes and several factors were significantly associated to this complication. To contribute to reduce mortality in patients with diabetes, cardiovascular autonomic neuropathy must systematically be investgated in follow up examination of patients when risk factors are present.

\section{Acknowledgments}

Not applicable

\section{Author's contributions}

All authors contributed equally to the manuscript; all authors read and approved the final version of the manuscript.

\section{Disclosure of potential conflicts of interest}

The authors declared that they have no conflict of interest.

\section{Funding}

This study received no financial support.

\section{References}

1. International Diabetes Federation. Atlas 2019.

2. Pichard E, Touré F, Traoré HA, Diallo AN. (1987). Les complications dégénératives du diabète sucré au Mali. Méd Af Noire. 34 : $404-411$.

3. Shera AS, Jawad F, Maqsood A, Jamal S, Azfar M, Ahmed U. (2004). Prevalence of chronic complications and associated factors in type 2 diabetes. Journal of Pakistan Medical Association. $54: 54-59$.

4. Panzram G. (1987). Mortality and survival in type 2 (non insulindependent) diabetes mellitus.Diabetologia. 30:123 -131.

5. Kempler P, Tesfaye S, Chaturvedi N, Stevens LK, Webb DJ, Eaton $S$ et al. (2002). Autonomic neuropathy is associated with increased cardiovascular risk factors : the EURODIAB IDDM complications study. Diabet Med. 19 : 900 -909.

6. Rytter L, Troelsen S, Beck-Nielsen H. (1985). Prevalence and mortality of acute myocardial infarction in patients with diabetes. Diabetes care. $8: 230-234$.

7. Ziegler D. (1994). Diabetic cardiovascular autonomic neuropathy: Prognosis, diagnosis and treatment. Diab Metab review. $10: 339-383$.

8. Pop-Busui R, Evans GW, Gerstein HC, Fonseca V, Fleg JL, Hoogwerf BJ et al. (2010). Effects of cardiac autonomic dysfunction on mortality risk in the Action to Control Cardiovascular risk in Diabetes (ACCORD) trial. Diabetes Care; $33: 1578-1584$.

9. Spallone V, Ziegler D, Freeman R, Bernadi L, Frontoni S, PopBusui R et al. (2011). On behalf of the Toronto Consensus Panel on diabetic neuropathy. Cardiovascular autonomic neuropathy in diabetes : clinical impact, assessment, diagnosis and management. Diabetes Metab Res Rev. 8 : 416-429.

10. Boullton AJ, Vinik AI, Arezzo JC, Bril V, Feldman EL, Freeman R, et al. (2005). Diabetic neuropathies: a statement by the American Diabetes Association. Diabetes Care. 28(4):956-962.

11. Low PA, Benrud-Larson LM, Sletten DM, Opfer-Gehrking TL, Weigand SD, O’Brien PC et al. (2004). Autonomic symptom and 
diabetic neuropathy : a population based study. Diabetes care ; $27: 2942$-2947.

12. Kennedy WR, Navarro X, Sutherland DE. (1995). Neuropatic profile of diabetic patients in pancreas transplantation program. Neurology; $45: 773-780$.

13. Wael R. (2014). Assessment of cardiovascular autonomic neuropathy in long standing type 2 diabetic women.The Egyptian Heart Journal; $66: 63$-69.

14. Pop-Busui R, Low PA, Waberski BH, Martin CL, Albers JW, Feldman EL et al. (2009). Effects of prior intensive insulin therapy on cardiac autonomic nervous system function in type 1 diabetes mellitus: the Diabetes Control and Complications Trial / Epidemiology of diabetes interventions and complications study (DCCT/EDICC). Circulation; 119 : 2886-2893.

15. Ko SH, Park SA, CHO JH, Song KH, Yoon KH, Cha BY et al. (2008). Progression of cardiovascular autonomic dysfuncction in patients with type 2 diabetes : a 7-year follow up study. Diabetes care; $31:$ 1832-1836.

16. Traoré D, Drago AA, Nientao IA, Sow DS, Menta I, Sidibe AT. (2014). Risque podologique chez les patients diabétiques dans un centre de référence de Bamako. Mali Médical; 29 : 14-18.

17. Ziegler D, Gries FA, Mühlen H, Rathmann W, Spüler M, Lessmann F. (1993). The Dia Can Multycenter study group. Prevalence and clinical correlates of cardiovascular autonomic and periferal diabetic neuropathy in patients attending diabetes centers. Diab Metab; 19 : 143-151.

18. Jaffe RS, Aoki TT, Rohatsch PL, Disbrow EA, Fung DL. (1995). Predicting cardiac autonomic neuropathy in type 1 (insulindependent) diadetes mellitus. Clinical Autonomic Research; 5 : 155-58.

19. Vinik AI, Freemann R, Erbas T. (2003). Diabetic autonomic neuropathy. Semin Neurol; $23: 365-372$.
20. Valensi P, Pariès J, Attali JR. (2003). Cardiac autonomic neuropathy in diabetic patients: Influence of diabetes duration, obesity and microangiopthic complications - the french multycenter study. Metabolism; 52 : 815-820.

21. Pop-Busui R. (2010). Cardiac autonomic neuropathy in diabetes: a clinical perspective. Diabetes care; $33: 434-441$.

22. Boulton AJ, Vinik AI, Arrezo JC, Bril V, Feldman EL, Freeman R et al. (2005). Diabetic neuropathy : a statement by the American Diabetes Association. Diabetes care; 28 : 956-962.

23. Ayad F, Belhady M, Pariès J, Attali JR, Valensi P. (2010). Association between cardiac autonomic neuropathy and hypertension and its potential influence on diabetic complications. Diabet Med; 27 : 804 -811.

24. Shoedmah-Muthu SS, Chatuverdi N, Witte DR, Stevens LK, Porta $\mathrm{M}$, Fuller JH et al. (2008). Relationship between risk factors and mortality in type 1 diabetic patients in Europe : the EURODIAB prospective complications study (PCS). Diabetes care ; $31: 1360$ 1366.

25. Tesfaye S, Chatuverdi N, Eaton SEM, Ward JD, Manes C, Ionescu-Tirgoviste $\mathrm{C}$ et al. (2005). Vascular risk factors and diabetic neuropathy. N Engl J Med; $352: 341-350$.

26. Graede P, Vedel P, Larsen N, Gensen GV, Parving HH, Pedersen O. (2003). Multifactorial intervention and cardiovascular disease in patients with type 2 diabetes. N Engl J Med ; 348 : 383-393.

27. Witte DR, Tesfaye S, Chatuverdi N, Eaton SE, Kempler P, Fuller JH, EURODIAB. (2005). Prospective Complications Study Group. Risk factors for cardiac autonomic neuropathy in type 1 diabetes mellitus. Diabetologia ; 48 : 164 -171.

28. Laitinen T, Lindstrom J, Erikson J, Ilane-Parikka P, Aunola S, Keinänen-Kiukaanniemi S et al. (2011). Cardiovascular autonomic dysfunction is associated with central obesity in persons with impaired glucose tolerance. Diabet Med ; 28 : 699 704.
This work is licensed under Creative Commons Attribution 4.0 License

To Submit Your Article Click Here: Submit Manuscript

DOI: $10.31579 / 2640-1045 / 083$
Ready to submit your research? Choose Auctores and benefit from:

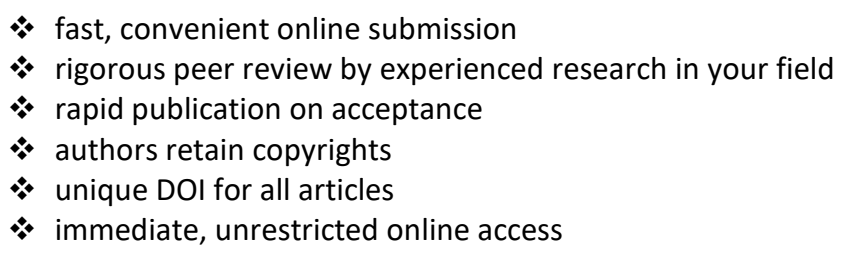

At Auctores, research is always in progress.

Learn more www.auctoresonline.org/journals/endocrinology-anddisorders 